\title{
Metric Data of the Ryukyuan Crania
}

\author{
Yukio Dodo ${ }^{1}$, Naomi Doi ${ }^{2}$, and Osamu Kondo ${ }^{3}$ \\ ${ }^{1}$ Department of Anatomy and Anthropology, Tohoku University School of Medicine, Sendai \\ ${ }^{2}$ Department of Anatomy, University of the Ryukyus, Okinawa \\ ${ }^{3}$ Department of Biological Sciences (Anthropology), Graduate School of Science, University \\ of Tokyo, Tokyo
}

(Received April 26, 2001; accepted April 29, 2001)

\begin{abstract}
Eighteen cranial measurements including 6 flatness measurements of the facial skeleton were taken for crania from the Amami, Okinawa, and Sakishima Islands, which constitute the Ryukyu Islands. The data will be useful for future multivariate statistical analyses of Ryukyuan crania.
\end{abstract}

Keywords: cranial measurements, facial flatness measurements, raw data, Ryukyu Islanders

Many near modern skeletal remains were found at burial caves (Fuso-baka) in the Ryukyu Islands, which consists of the islands of Amami, Okinawa, and Sakishima. Using these skeletal materials, we initiated a joint research project "Anthropological Reexamination of Skeletal Remains from the Ryukyu Islands" in 1993. This research project has yielded the two articles that refute the so-called Baelz's "Ainu-Ryukyu common origin theory", based on cranial nonmetric variation and flatness of facial skeletons (Dodo et al., 1998, 2000). However, as reported in Dodo (2001), craniometric analyses of the Ryukyu Islanders were not successful because two different definitions of upper facial height were used to make comparisons.

The present report is the final work of our joint research project and provides 18 cranial measurements for each cranium of the male and female series from the Ryukyu Islands.

\section{Materials}

Well-preserved crania in which all 18 measurements could be obtained were used. These materials consisted of 15 male and 13 female crania from the Amami Islands, 22 male and 21 female crania from the Okinawa Islands, and 23 male and 13 female crania from the Sakishima Islands. Sex determination was made based mainly on the

Corresponding author: Yukio Dodo

Department of Anatomy and Anthropology, Tohoku University School of Medicine

2-1 Seiryo-machi, Aoba-ku, Sendai, Miyagi 980-8575, Japan

E-mail: dodo@mail.cc.tohoku.ac.jp 
Table 1. Cranial measurements

\begin{tabular}{lcl}
\hline Measurement & (Abbreviation) & Method \\
\hline Maximum cranial length & (L) & Martin \#1 \\
Basion-nasion length & (BL) & Martin \#5 \\
Maximum cranial breadth & (B) & Martin \#8 \\
Minimum frontal breadth & (FB) & Martin \#9 \\
Basion-bregma height & (H) & Martin \#17 \\
Basion-prosthion length & $(\mathrm{GL})$ & Martin \#40 \\
Bizygomatic breadth & $(\mathrm{J})$ & Martin \#45 \\
Upper facial height & $\left(\mathrm{G}^{\prime} \mathrm{H}(\mathrm{H})\right)$ & Howells NPH \\
Orbital breadth & $(\mathrm{OB})$ & Martin \#51 \\
Orbital height & $(\mathrm{OH})$ & Martin \#52 \\
Nasal breadth & $(\mathrm{NB})$ & Martin \#54 \\
Nasal height & $(\mathrm{NH})$ & Martin \#55 \\
Frontal chord & $(\mathrm{FC})$ & Yamaguchi (1973) \\
Frontal subtense & (FS) & ditto \\
Simotic chord & $(\mathrm{SC})$ & ditto \\
Simotic subtense & $(\mathrm{SS})$ & ditto \\
Zygomaxillary chord & (ZC) & ditto \\
Zygomaxillary subtense & (ZS) & ditto \\
\hline
\end{tabular}

size and shape of the cranium because of the difficulty of identifying whole skeletons in cave burials.

Many of these materials were from university collections and are housed in Kyoto University, University of the Ryukyus, and University of Tokyo. However, some crania from the Okinawa Islands and many from the Sakishima Islands were studied insitu at the burial caves at Gyokusendo in Okinawa Honto and Nagabaka on Miyako Island.

These cranial samples are believed to date from the early modern Edo period (ca. 1600-1900 A.D.).

\section{Methods}

The 18 cranial measurements are listed in Table 1. Abbreviations for these measurements shown in Table 1 are tentatively defined by the present authors.

With the exception of the upper facial height, the 11 traditional measurements were carried out after Martin (1914). The upper facial height was measured from the nasion to prosthion as defined by Howells (1973). When comparing the upper facial height of Howells (nasion prosthion) with that of Martin (nasion alveolare), it is recommended that $2.5 \mathrm{~mm}$ in males and $2.0 \mathrm{~mm}$ in females are added to the Howells' upper facial height (Dodo, 2001). 
n Nิ

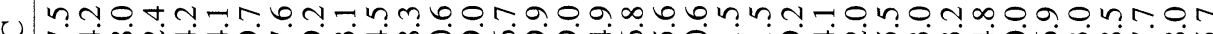

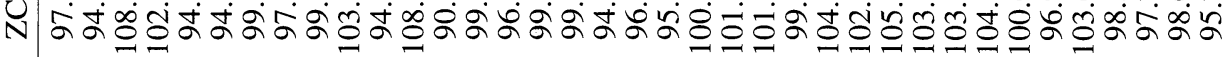

m m

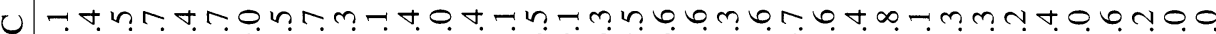
ज ấa

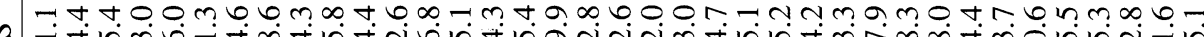

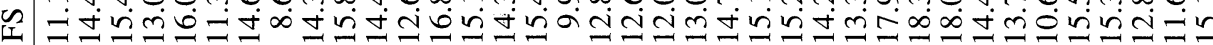
toom

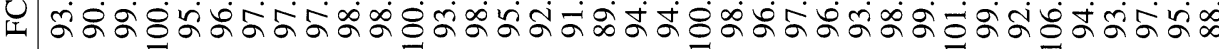

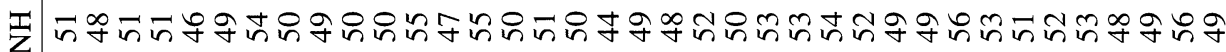

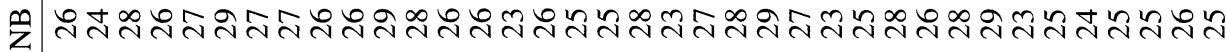

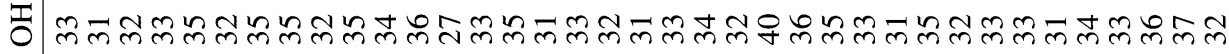

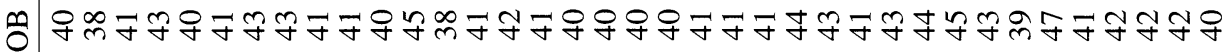

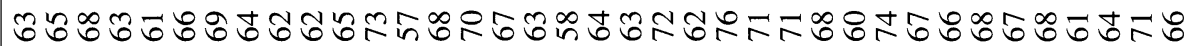

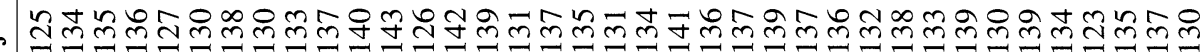

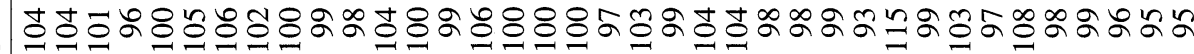

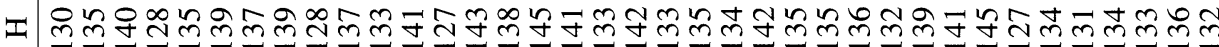

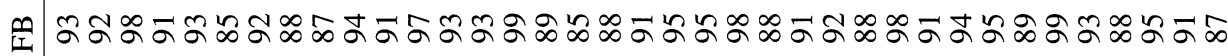

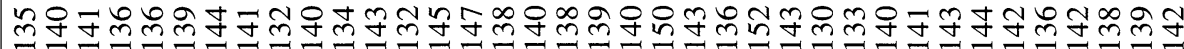

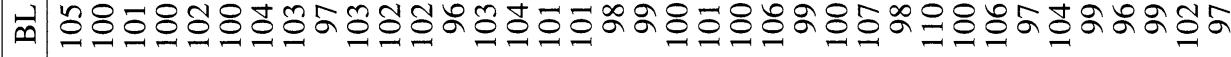

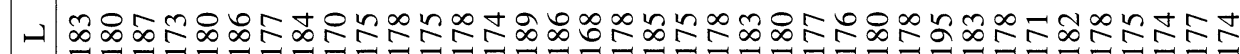
ज小山A 


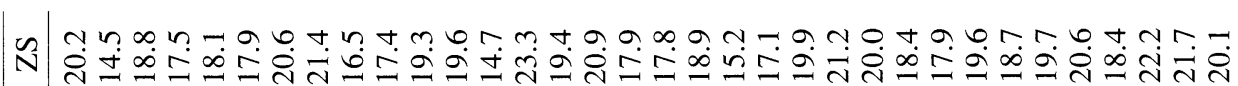

U mon

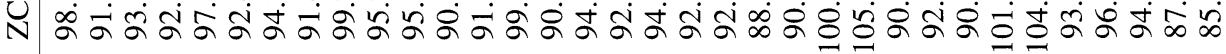

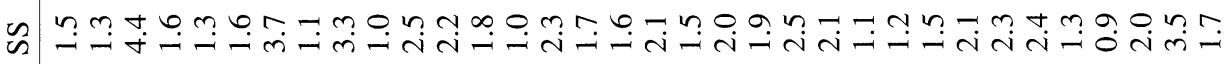

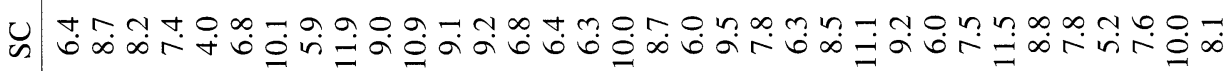

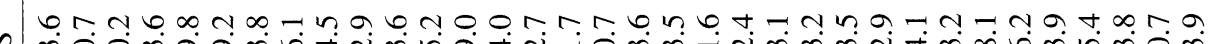

ص

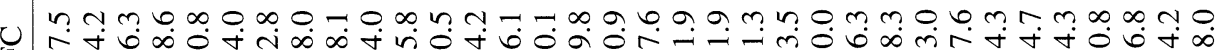

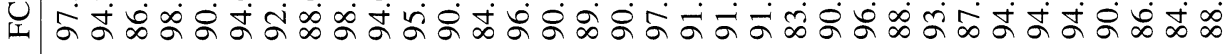

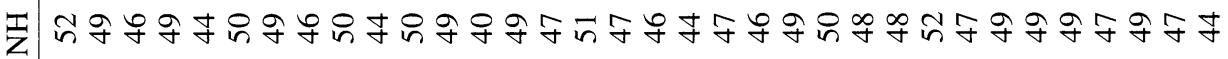

艺

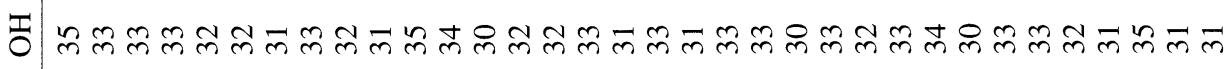

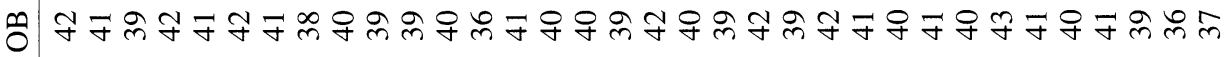

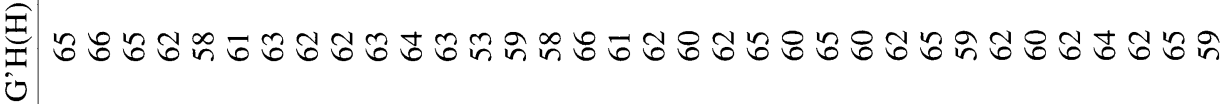

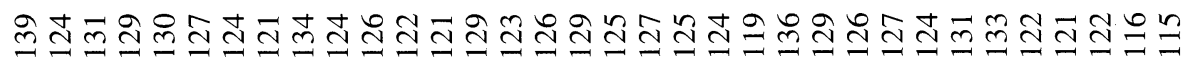

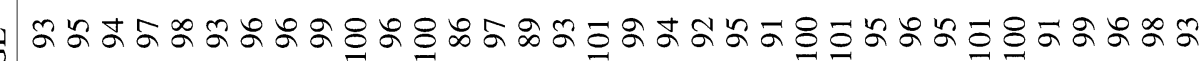

অ

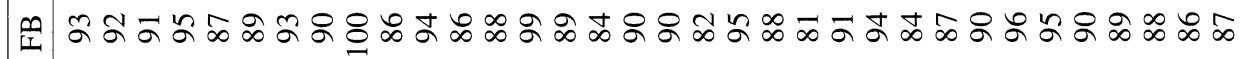

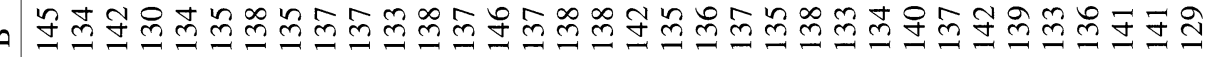

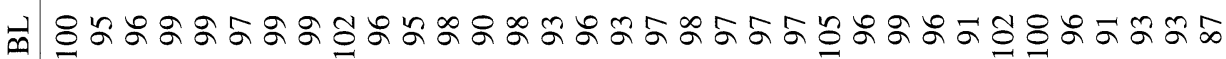

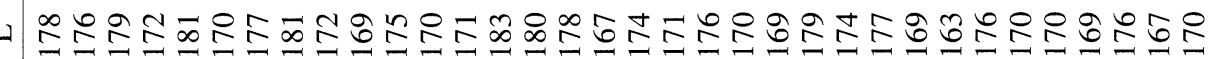

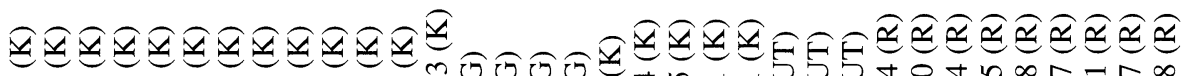

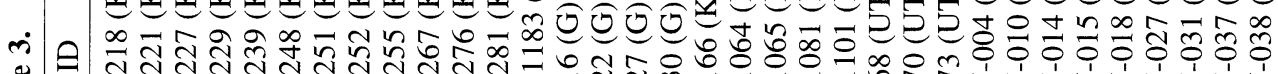




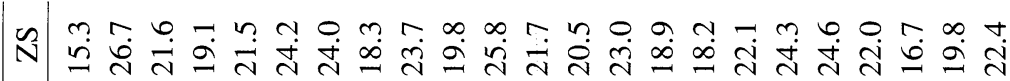
N

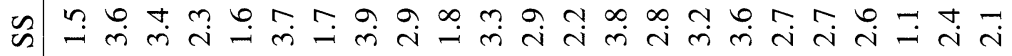
U L

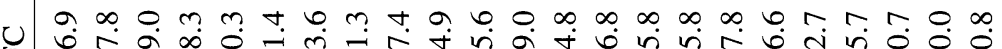

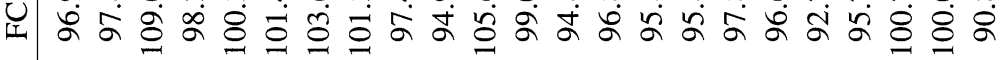

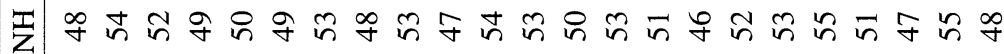
茓 ปస్ ๑ี 预

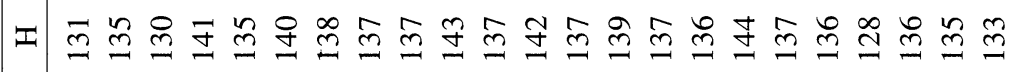
田 $\stackrel{\Xi}{\Xi}$

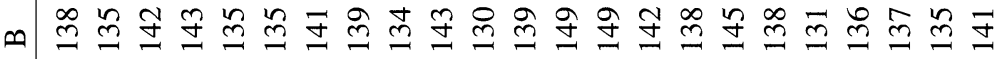
๓

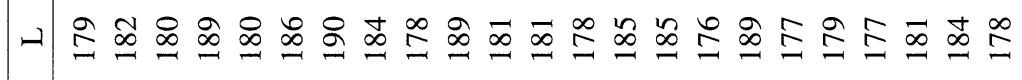
๔ِ

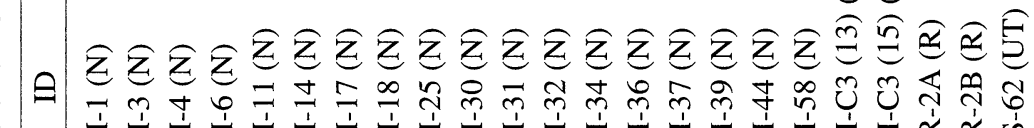
产

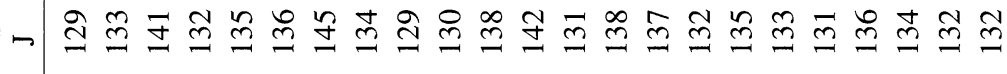

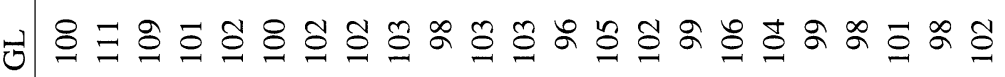




\begin{tabular}{|c|c|}
\hline$\tilde{N}$ & 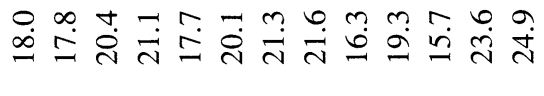 \\
\hline$\stackrel{U}{N}$ & 范 \\
\hline$\approx$ & 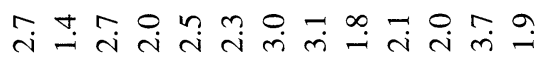 \\
\hline$\underset{\mathscr{U}}{U}$ & 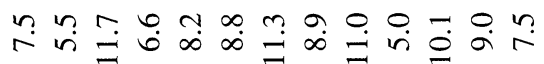 \\
\hline$\left[\begin{array}{c}2 \\
2\end{array}\right.$ & 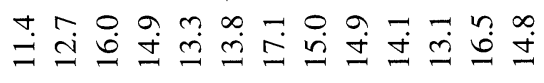 \\
\hline U & 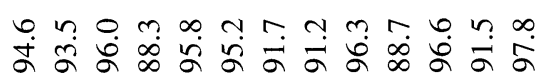 \\
\hline 罗 & 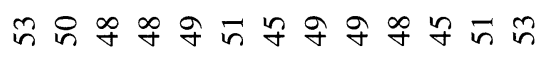 \\
\hline 竞 & 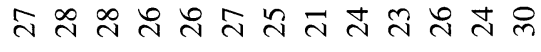 \\
\hline T: & m̄ \\
\hline$\approx$ & 위 가 하 \\
\hline$\underset{\underbrace{}}{\underline{I}}$ & ชิ ชช \\
\hline$\neg$ & 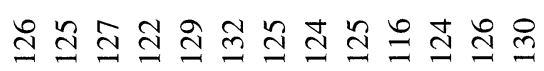 \\
\hline $\overrightarrow{0}$ & 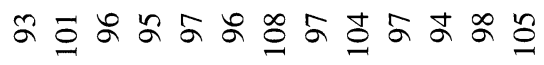 \\
\hline $\mathbf{I}$ & 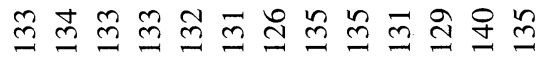 \\
\hline 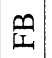 & 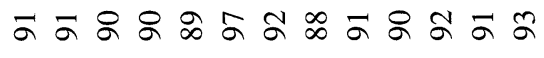 \\
\hline$\infty$ & 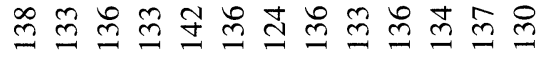 \\
\hline$\vec{n}$ & 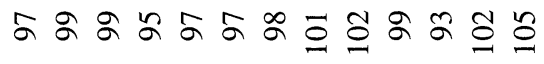 \\
\hline - & 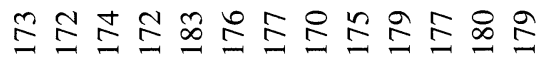 \\
\hline A & 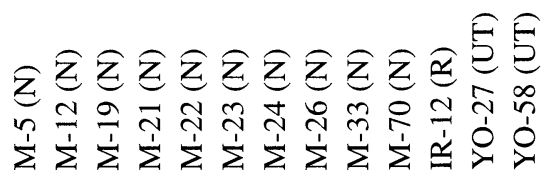 \\
\hline
\end{tabular}


The remaining 6 measurements were those assessing the transverse flatness of facial skeletons as described by Yamaguchi (1973).

\section{Craniometric Raw Data}

Taking the geographically and culturally close relationship between the Amami and Okinawa Islanders into consideration (e.g., Fujimoto, 1988; Asato, 1996), these two groups were combined as a single population unit. Craniometirc raw data for the Amami/Okinawa Islanders are shown in Table 2 for males and Table 3 for females. The raw data of the male and female Sakishima Islanders are given in Tables 4 and 5, respectively.

In these tables, the capital letter prefixed to an ID number represents the name of the island from which the cranium is derived: $\mathrm{T}$ and $\mathrm{KI}$ stand for Tokunoshima and Kikai-jima of the Amami islands group; $\mathrm{H}$ and $\mathrm{KU}$ stand for Okinawa Honto and Kume-jima of the Okinawa islands group; M, IR, IS, and YO, respectively, indicate Miyako-jima, Iriomote-jima, Ishigaki-jima, and Yonaguni-jima of the Sakishima islands group. The capital letter in parenthesis following an ID number represents the location where the cranium is kept: K, UT, and R, respectively, stand for Kyoto University, University of Tokyo, and University of the Ryukyus; G and N designate the Gyokusendo burial cave of Okinawa Honto and the Nagabaka burial cave of Miyako-jima.

For more extensive data of Ryukyuan mean cranial measurements, see Ikeda (1974), and Tagaya and Ikeda (1976).

\section{Acknowledgments}

Institutions and individuals that made this study possible have been acknowledged in the previous paper (Dodo et al., 1998). This study was supported in part by Grantin-Aid for Scientific Research (Nos. 0564085 and 07304058) and Grant-in-Aid for Scientific Research on Priority Areas (No. 09208104) from the Ministry of Education, Science, Sports, and Culture.

\section{References}

Asato S. (1996) Population history of modern Ryukyuans viewed from archaeology. Journal of Geography, 105: 364-371 (in Japanese with English summary).

Dodo Y. (2001) Different measurement methods of upper facial height strongly influence the results of craniometric analyses: Metric study of the Ainu and Ryukyuan crania. Anthropological Science (Jpn Series), 108: 133-141 (in Japanese).

Dodo Y., Doi N., and Kondo O. (1998) Ainu and Ryukyuan cranial nonmetric variation: Evidence which disputes the Ainu-Ryukyu common origin theory. Anthropological Science, 106: 99-120. 
Dodo Y., Doi N., and Kondo O. (2000) Flatness of facial skeletons of Ryukyuans. Anthropological Science, 108: 183-198.

Fujimoto T. (1988) Two Other Japanese Cultures: The Cultures of Hokkaido and Southern Islands. University of Tokyo Press, Tokyo (in Japanese).

Howells, W.W. (1973) Cranial Variation in Man: A Study by Multivariate Analysis of Patterns of Difference among Recent Human Populations. Peabody Museum of Archaeology and Ethnology, Harvard University, Cambridge.

Ikeda J. (1974) Craniometry of Miyako Islanders, the Ryukyus. Journal of the Anthropological Society of Nippon, 82: 150-160 (in Japanese with English summary).

Martin R. (1914) Lehrbuch der Anthropologie. Gustav Fischer, Jena.

Tagaya A. and Ikeda J. (1976) A multivariate analysis of the cranial measurements of the Ryukyu Islanders (males). Journal of the Anthropological Society of Nippon, 84: 204-220.

Yamaguchi B. (1973) Facial flatness measurements of the Ainu and Japanese crania. Bulletin of the National Science Museum, 16: 161-171.

Editor-in-Charge: Hajime Ishida 